\title{
Mental health in the Dominican Republic
}

\author{
Miguel R. Hernández MD, ${ }^{1}$ Tresha Ann Gibbs MD² and \\ Luisa Gautreaux-Subervi MD
}

${ }^{1}$ Attending and Clinical Instructor in Psychiatry, New York Presbyterian Hospital, Columbia University College of Physicians and Surgeons, USA, email mh2330@columbia.edu; 2PGY-IV Psychiatry Chief Resident, Columbia Presbyterian Hospital and New York State Psychiatric Institute, USA; ${ }^{3}$ Sub-director of Padre Billini Psychiatric Hospital, Santo Domingo, Dominican Republic

$T^{\text {the }}$ he Dominican Republic is located in the Caribbean Sea and comprises three-quarters of the island Hispaniola, which it shares with Haiti. According to the 2002 census, approximately 8.5 million people live in the Republic, with $64 \%$ residing in urban areas (Oficina Nacional Estadística, n.d.). During 1990 and 2000, the Dominican Republic was a leader in economic development for Latin America and the Caribbean; however, this was not reflected in the areas of human and social development (Pan American Health Organization \& World Health Organization, 2007). Less than $1 \%$ of the health budget administered by the Ministry of Public Health and Social Assistance (MISPAS) is allocated to mental health and the public system is generally underfunded (Pan American Health Organization \& World Health Organization, 2008). However, there is an array of mental health services within the country when privately funded facilities are taken into account.

In the Dominican Republic, it is estimated that the most common mental disorders are mood disorders, substance misuse, schizophrenia, intellectual disability and epilepsy. Depression has a prevalence of $1.9 \%$ for males and $3.7 \%$ for females, with $5.8 \%$ of men and $9.8 \%$ of women experiencing a depressive episode at least once yearly (Sánchez-Martinez, 2006). Approximately 80000 Dominicans carry the diagnosis of schizophrenia and half of them receive inadequate followup and treatment (Sánchez-Martinez, 2006). Psychosocial factors that play a role in the mental health of Dominicans include poverty, violence, physical abuse, sexual abuse, exploitation of minors and the sequelae of substance misuse.

\section{Mental health policy and legislation}

In recent decades, the Dominican Republic has undergone enormous economic and social transformation, driven by global changes and national trends. In the health sector, one major change was the approval of the General Health Law (no. 42-01), enacted in 2001, and the Law Establishing the Dominican Social Security System (no. 87-01), of 1987. These laws were followed by the integration of the National Mental Health System into the National Health System and the Dominican social security system (Ministerio de Salud Pública y Asistencia Social, 2004). The General Health Law regulates all activities that make it possible for the state to ensure the right to health, while the Law Establishing the Dominican Social Security System laid the groundwork for the development of a social protection system with universal coverage, promoting the growth of insurance coverage via social contributions by employers, employees and the government (Alarcon, 2003).

The regulation of mental healthcare within a framework of rights of persons with such disabilities was established by the Minister of Health through enactment of the Mental Health Law in February 2006. It stated the basic rights and freedoms of people who are mentally ill and established that the 'objective is to regulate the right to the best care available in mental health of all persons under the provisions of the General Health Law'. Chapter II, article 10, provides that there are 'basic rights and fundamental freedoms of persons with a mental illness' (Ministerio de Salud Pública y Asistencia Social, 2006). The current mental health policy is consistent with the Mental Health Law and is overseen by a national authority in MISPAS.

The Dominican government has a 10-year health plan (2006-15). Its mental health component aims to improve mental health service delivery within primary care and to reform the main public hospital, the Padre Billini Psychiatric Hospital. Progress is ongoing (Pan American Health Organization \& World Health Organization, 2008).

\section{Mental health service delivery}

Mental health services are primarily located in urban areas, as are medical professionals more generally. There is one major public psychiatric hospital, Padre Billini Psychiatric Hospital, located near the capital, Santo Domingo. It provides inpatient and out-patient services to patients aged $16-65$ years and plays a very important role in the delivery of mental healthcare in the Dominican Republic. Approximately 50\% of national public mental health funding goes to the Padre Billini Hospital. The in-patient service has approximately 130 beds, 60 of which are occupied by patients who have no options for discharge and therefore reside permanently in the hospital (World Health Organization, 2005).

The current plan is to decentralise mental health services by closing this facility, opening new psychiatric in-patient units in medical hospitals, optimising the current in-patient units, updating the mental health community centres, and creating a supervised residence for people with chronic mental illness. This decentralisation has been ongoing since 1997 and aims to reduce the number of in-patient beds while increasing out-patient services and integrating mental health with primary care (World Health Organization, 2005). 
The Ministry of Health has 256 psychiatric beds available nationally, with the capacity to serve approximately 9000 patients. Of these beds, $65 \%$ are located in the Padre Billini Psychiatric Hospital and 35\% in the 47 psychiatric units distributed throughout hospitals in Santo Domingo, Santiago, San Francisco de Macoris, Barahona and other cities. Most of these units provide out-patient services.

There are a few privately funded in-patient acute and longterm treatment facilities in the major cities. Privately funded in-patient substance rehabilitation centres are also available.

There are no in-patient psychiatric units for children. Only $4 \%$ of out-patient services are focused on treating children.

Costs associated with mental healthcare are shared by the public system, some private insurance and by families. Disability benefits exist for people with mental disorders. Those outside the public system incur significant out-ofpocket expenses for in-patient services and medications at the private hospitals.

One policy used by certain public in-patient units is to admit patients with a family member. This family member serves to advocate for the patient, maintains patient comfort, and ensures a timely discharge plan. This reduces prolonged hospital stays and allows the unit to admit new, acutely ill patients.

The government-sponsored services have a limited list of essential medications, including antidepressants, antipsychotics, mood stabilisers and anxiolytics, consistent with the World Health Organization's recommended medications. In the private sector, there is a broader range of medications, available in part due to marketing from local and international pharmaceutical companies. Electroconvulsive therapy remains a commonly used treatment, as it is considered safe and effective for mood and psychotic disorders.

\section{Undergraduate and postgraduate psychiatric training}

There has been a robust programme of psychiatry training in the Dominican Republic since 1977. The current programme lasts 4 years, with the first year exclusively for internal medicine rotations. All psychiatry residents complete undergraduate and medical school requirements. Training in psychiatry is primarily conducted at the Padre Billini Psychiatric Hospital. Residents get experience in in-patient and out-patient psychiatry. They are trained in mood disorders, psychosis, substance misuse disorders, child psychiatry, human sexuality, epidemiology and neuro-radiology. As a requirement for graduation, each resident has to complete a thesis. Residents have the opportunity to do international electives in Costa Rica, Panama, Spain or the USA. There are currently 18 psychiatry residents at the Padre Billini Hospital. Another residency programme, located in the city of Santo Domingo at the Salvador Gautier Hospital, has four psychiatry residents. Both residency programmes have an affiliation with the Universidad Autónoma de Santo Domingo (UASD).

\section{Workforce issues and resources}

There are approximately 210 psychiatrists in the Dominican Republic, but there are insufficient mental health nurses, social workers and occupational therapists. There are no fellowship training programmes for these disciplines. There is, though, a large and increasing number of psychologists, as well as a small number of child psychiatrists and substance misuse specialists, some trained in fellowships abroad.

There are national associations for psychiatrists, specifically the Association of Psychiatrists from Dominican Residency Programs (ASPERDO), Colegio Dominicano de Neuropsicofarmacología and the Dominican Society of Psychiatry. The last was founded in 1968 and is a subsidiary of the Dominican Medical College, the World Psychiatric Association, the Latin American Psychiatric Association and the Central American Psychiatric Association.

Regionally, human mental health resources in Latin America are scarce. The estimated figures of 1.6 psychiatrists, 2.7 psychiatric nurses, 2.8 psychologists, and 1.9 social workers per 100000 are far below those of Europe or the USA (Alarcon, 2003). Their training takes place in facilities that have limited teaching staff, not enough equipment and limited monitoring by academic centres or governmental agencies. In spite of some slight growth in the absolute numbers of psychiatrists, this threatens to be lost through the emigration of trainees. The Dominican Republic is no exception to this regional situation.

\section{Main areas of research}

There is some research ongoing in the Dominican Republic under the umbrella of universities (see for example the websites of the Colegio Dominicano de Neuropsicofarmacologia, www. cdnp.org.do, and of the Instituto de Sexualidad Humana, www.institutodesexualidadhumana.org). A PubMed search for articles on mental health in the Dominican Republic yielded no articles. More support for research and training in research is needed. A centralised system of data collection exists with some limitations and over time will allow for more systematic data collection, which will yield important statistics about the effect of psychiatric disorders on Dominicans.

\section{Human rights issues}

The Dominican Republic has human rights training for employees working in certain in-patient psychiatric units and community residential facilities (Pan American Health Organization \& World Health Organization, 2008).

\section{References}

Alarcon, R. (2003) Mental health and mental health care in Latin America. World Psychiatry, 2, 54-56.

Ministerio de Salud Pública y Asistencia Social (2004) Normas Nacionales para la Atención en Salud Mental, 500 Ejemplares [National Norms for Mental Health, 500 Examples] (1st edition), pp. 13, 14. Editora Búho. Ministerio de Salud Pública y Asistencia Social (2006) Comisión Ejecutiva para la Reforma del Sector Salud: Ley sobre Salud Mental No. 12-06 [Executive Commission for Health Sector Reform: Mental Health Law], pp. 7,8, 9, 11-13, 15,16, 22-25. Editora Búho. Available at http://www.suprema.gov.do/pdf/leyes/2006/ley_12-06.pdf (accessed November 2010).

Oficina Nacional Estadística (n.d.) Dominican statistics website, http:// www.gob.do (accessed October 2010). 
Pan American Health Organization \& World Health Organization (2007) Perfil De Los Sistemas De Salud De La Republica Dominicana: Monitoreo y Analisis De Los Procesos De Cambios y Reforma [Dominican Republic Health System Profile] (3rd edition). PAHO/WHO.

Pan American Health Organization \& World Health Organization (2008) Report on the Assessment of Mental Health Systems in the Dominican Republic Using the WHO Assessment Instrument for Mental Health Systems (WHO-AIMS). PAHO/WHO. Available at http://www.who. int/mental_health/dominican_republic_who_aims_eng.pdf (accessed October 2010).

Sánchez Martínez, F. (2006) Psiquiatría Dominicana [Dominican Psychiatry], pp. 98, 104, 262-264, 275-277. Editora Búho.

World Health Organization (2005) Mental Health Atlas: Dominican Republic, pp. 172-173. WHO. Available at http://www.who.int/ mental_health/evidence/atlas/profiles_countries_c_d.pdf (accessed October 2010).

\title{
Perceived coercion and need for hospital admission among psychiatric in-patients: figures from a Pakistani tertiary care hospital
}

\section{Saman I. Zuberi FCPS, ${ }^{1}$ Ayesha Sajid MD, ${ }^{2}$ Abdul Wahab Yousafzai FCPS, ${ }^{3}$ Naila Bhutto FCPS ${ }^{4}$ and Murad Moosa Khan MRCPsych ${ }^{5}$}

\begin{abstract}
'Department of Psychiatry, Aga Khan University, Karachi, Pakistan, email saman.yousuf.zuberi@gmail.com; ${ }^{2}$ PGYII, Department of Psychiatry, Indiana University School of Medicine, USA; ${ }^{3}$ Assistant Professor, Department of Psychiatry, Ayub Medical College and Visiting Faculty, Department of Psychiatry, Aga Khan University; ${ }^{4}$ nstructor and Consultant Psychiatrist, Department of Psychiatry, Aga Khan University; ${ }^{5}$ Chair, Department of Psychiatry, Aga Khan University Hospital
\end{abstract}

\begin{abstract}
n Pakistan, an increasing proportion of psychiatric patients present to community health services as crisis admissions, with their relatives as the main decision makers. Patients are bound to perceive this process as coercive. Farnham \& James (2000) report that elements of coercion are found even in voluntary hospital admission, in the form of verbal persuasion, physical force and threats of commitment. Few patients consider hospitalisation justified and most view the process of admission negatively (Swartz et al, 2003; Katsakou \& Priebe, 2006; Priebe et al, 2009).

Perceptions of coercion depend on context and are subject to cultural differences. Unfortunately, there is no study from Pakistan, a low-income country with unregulated mental health services, where sections of Mental Health Act 2001 are loosely followed at best (Gilani et al, 2005). Most mental health facilities define 'involuntary admission' as the situation where the family brings a patient against his or her will and a physician takes a decision after assessment without due legal procedures or recourse to appeal.

We explored perceptions of coercion and hospitalisation among patients admitted to a psychiatric unit in Karachi. The unit accepts compulsory admissions advised by courts for assessment (this is uncommon). The Mental Health Act 2001 is not used formally. We looked for associated patient characteristics.
\end{abstract}

\section{Method}

Patients admitted to the psychiatric in-patient unit (a 16-bed adult unit) of Aga Khan University Hospital were sampled. Patients 18 years or older, admitted with any psychiatric diagnosis, were enrolled. Younger patients and those with intellectual disability, cognitive impairment or acute psychotic symptoms were excluded. Patient characteristics were recorded: gender, age, marital status, language, occupation and education, clinical diagnosis, admission type (first $v$. repeat) and nature (voluntary $v$. involuntary).

Each patient was administered the MacArthur Admission Experience Survey (AES; Nicholson et al, 1996), which comprises 15 items in a true/false format. This scale was translated into Urdu by bilingual translators and administered to 20 patients before the study. Difficulties were resolved by consensus. The AES has good internal reliability (Gardner et al, 1993). It contains four subscales with yes/no responses: the Perceived Coercion Scale (PCS, 5 items), which has an equivalent consistency and test-retest reliability, the Negative Pressures Scale (NPS, 6 items), the Voice/Process Exclusion Scale (PES, 3 items) and the Affective Reactions to Hospitalisation Scale (1 item). Scoring involved summing over the whole scale (except items 9 and 15) as well as the first three subscales, as has been done in other studies (Gardner et al, 1993). A cut-off score of 2 on the PCS was used to split 